\title{
On the stratospheric chemistry of hydrogen cyanide
}

\author{
Armin Kleinböhl, ${ }^{1}$ Geoffrey C. Toon, ${ }^{1}$ Bhaswar Sen, ${ }^{1}$ Jean-François L. Blavier, ${ }^{1}$ \\ Debra K. Weisenstein, ${ }^{2}$ Rafal S. Strekowski, ${ }^{3}$ J. Michael Nicovich, ${ }^{4}$ Paul H. Wine,,${ }^{4,5}$ \\ and Paul O. Wennberg ${ }^{6}$
}

Received 9 February 2006; revised 30 March 2006; accepted 24 April 2006; published 3 June 2006.

[1] HCN profiles measured by solar occultation spectrometry during 10 balloon flights of the JPL MkIV instrument are presented. The HCN profiles reveal a compact correlation with stratospheric tracers. Calculations with a 2D-model using established rate coefficients for the reactions of $\mathrm{HCN}$ with $\mathrm{OH}$ and $\mathrm{O}\left({ }^{1} \mathrm{D}\right)$ severely underestimate the measured $\mathrm{HCN}$ in the middle and upper stratosphere. The use of newly available rate coefficients for these reactions gives reasonable agreement of measured and modeled HCN. An HCN yield of $\sim 30 \%$ from the reaction of $\mathrm{CH}_{3} \mathrm{CN}$ with $\mathrm{OH}$ is consistent with the measurements. Citation: Kleinböhl, A., G. C. Toon, B. Sen, J.-F. L. Blavier, D. K. Weisenstein, R. S. Strekowski, J. M. Nicovich, P. H. Wine, and P. O. Wennberg (2006), On the stratospheric chemistry of hydrogen cyanide, Geophys. Res. Lett., 33, L11806, doi:10.1029/2006GL026015.

\section{Introduction}

[2] Hydrogen cyanide ( $\mathrm{HCN})$ was first detected in the Earth's stratosphere by means of airborne infrared absorption spectrometry [Coffey et al., 1981], and shortly later by microwave techniques [Carli et al., 1982]. Profile information on $\mathrm{HCN}$ in the stratosphere was obtained by several remote measurements [Abbas et al., 1987; Zander et al., 1988; Jaramillo et al., 1988, 1989]. Tropospheric HCN was first detected by Rinsland et al. [1982] using ground-based infrared absorption spectrometry. This work was followed by several other studies based on infrared absorption measurements, most recently by Kasai et al. [2005] and Rinsland et al. [2005]. In-situ detections of HCN have been achieved by mass spectrometric methods in the stratosphere [Spreng and Arnold, 1994; Schneider et al., 1997] and more recently gas chromatographic methods in the troposphere [Singh et al., 2003].

[3] $\mathrm{HCN}$ is produced in the troposphere mainly by biomass burning and to a lesser extent by coal burning [Li et al., 2003]. Uptake into the ocean has been suggested to be the major tropospheric loss mechanism [ $L i$ et al.,

\footnotetext{
${ }^{1}$ Jet Propulsion Laboratory, California Institute of Technology, Pasadena, California, USA.

${ }^{2}$ Atmospheric and Environmental Research, Inc., Lexington, Massachusetts, USA.

${ }^{3}$ School of Earth and Atmospheric Science, Georgia Institute of Technology, Atlanta, Georgia, USA.

${ }^{4}$ School of Chemistry and Biochemistry, Georgia Institute of Technology, Atlanta, Georgia, USA.

${ }^{5}$ Also at School of Earth and Atmospheric Science, Georgia Institute of Technology, Atlanta, Georgia, USA.

${ }^{6}$ California Institute of Technology, Pasadena, California, USA.
}

Copyright 2006 by the American Geophysical Union. 0094-8276/06/2006GL026015
2003]. Removal also occurs by the reaction with $\mathrm{OH}$ [Cicerone and Zellner, 1983]. Chemical loss of HCN in the stratosphere is primarily caused by the reactions with $\mathrm{OH}$ and $\mathrm{O}\left({ }^{1} \mathrm{D}\right)$, and by photolysis. Modeling of stratospheric HCN was undertaken by Cicerone and Zellner [1983] and Brasseur et al. [1985]. However, measurements of $\mathrm{HCN}$ exceeded their 1D-model calculations at altitudes above $\sim 20-25 \mathrm{~km}$. In addition, a connection between atmospheric $\mathrm{HCN}$ and $\mathrm{CH}_{3} \mathrm{CN}$ had been proposed [Murad et al., 1984]. Brasseur et al. [1985] investigated $\mathrm{HCN}$ as a progenitor of $\mathrm{CH}_{3} \mathrm{CN}$ but concluded that this was unlikely.

[4] Here we present a new set of atmospheric $\mathrm{HCN}$ volume mixing ratio (VMR) profiles from balloon-borne infrared solar occultation measurements by the Jet Propulsion Laboratory (JPL) MkIV interferometer [Toon, 1991] between 1994 and 2004. We compare measured HCN-tracer correlations with 2D-model calculations that apply (1) rate coefficients for $\mathrm{HCN}$ destruction by $\mathrm{OH}$ based on the JPL recommendation [Sander et al., 2003] and by $\mathrm{O}\left({ }^{1} \mathrm{D}\right)$ based on the assumption by Cicerone and Zellner [1983], and (2) newly available rate coefficients for these reactions recently determined from laboratory measurements [Strekowski, 2001]. We show that the new rate coefficients significantly improve the agreement between measurements and model, and investigate the role of $\mathrm{CH}_{3} \mathrm{CN}$ as a possible source of $\mathrm{HCN}$.

\section{HCN Solar Occultation Measurements}

[5] Simultaneous measurements of VMR profiles of HCN and more than 30 other stratospheric gases were taken by the JPL MkIV Fourier transform interferometer. The MkIV covers a spectral range between 650 and $5650 \mathrm{~cm}^{-1}$ with a spectral resolution of $\sim 0.01 \mathrm{~cm}^{-1}$. During balloonborne operation, the MkIV views the sun through the atmospheric limb at sunset or sunrise, providing a high sensitivity to trace gases due to the long paths through the atmosphere. The measured sunset and sunrise spectra are ratioed against an exo-atmospheric spectrum derived from low-airmass measurements from float altitude.

[6] The retrieval of the VMR of atmospheric trace gases is performed in two stages: First, spectral fitting is performed using a nonlinear least squares algorithm to determine the slant column abundances of each target gas in each spectrum. Second, a vertical profile is retrieved by solving the matrix equation that relates the measured slant columns to the calculated geometrical slant paths on a vertical grid of $2 \mathrm{~km}$ spacing. For this, a linear equation solver is used together with a smoothing constraint.

[7] For the HCN retrieval 23 microwindows in a frequency band between 3254 and $3362 \mathrm{~cm}^{-1}$ are analyzed 


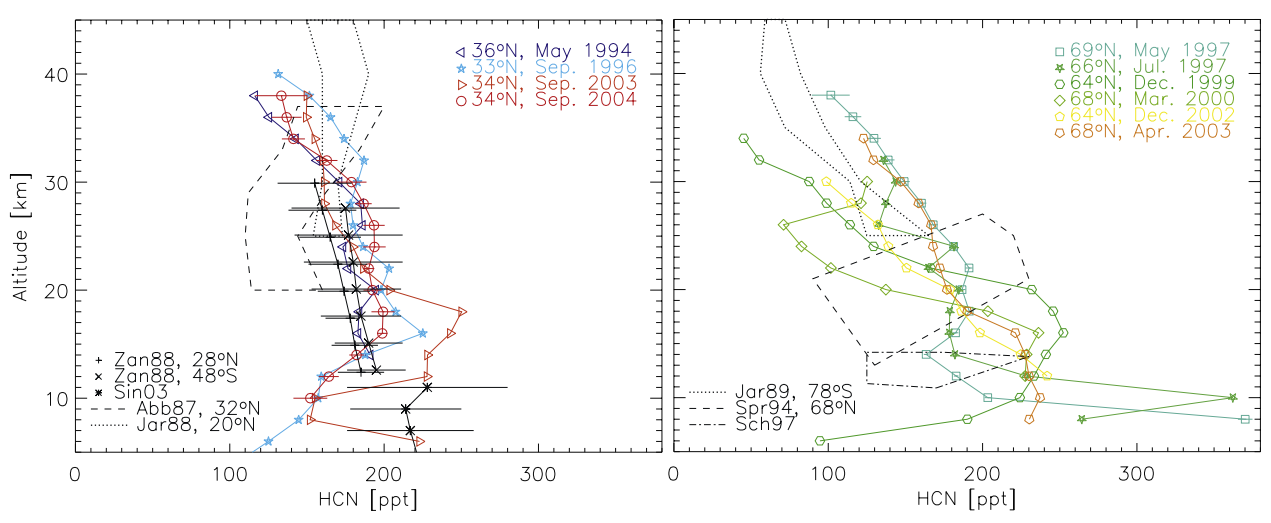

Figure 1. Retrieved vertical profiles of HCN from 10 balloon flights between 1994 and 2004 vs. altitude measured by the MkIV instrument at mid-latitudes (left) and at polar latitudes (right). The error bars (only given for one profile in each plot for clarity) give the precisions. Also included are profile measurements from literature sources (spaceborne infrared solar occultation measurements [Zander et al., 1988], airborne gas chromatographic measurements [Singh et al., 2003], balloonborne far-infrared measurements [Abbas et al., 1987], ground-based microwave measurements [Jaramillo et al., 1988, 1989], balloon-borne mass spectrometric measurements [Spreng and Arnold, 1994], airborne mass spectrometric measurements [Schneider et al., 1997]).

(see auxiliary material ${ }^{1}$ ). The HCN line parameters have been subject of a major revision in the latest version of HITRAN [Rothman et al., 2005]. The use of these line parameters give better consistency between microwindows compared to previous versions of HITRAN, and lead to HCN VMRs that are about $10 \%$ higher. The determined slant columns for each spectrum are a weighted average of the slant columns retrieved in all microwindows.

[8] The present analysis comprises 10 balloon flights, which were performed between 1994 and 2004. Four flights were launched from Ft. Sumner, NM $\left(34.5^{\circ} \mathrm{N}, 104.2^{\circ} \mathrm{W}\right)$, two from Fairbanks, $\mathrm{AK}\left(64.8^{\circ} \mathrm{N}, 147.7^{\circ} \mathrm{W}\right)$, and four from Esrange, Sweden $\left(67.9^{\circ} \mathrm{N}, 21.1^{\circ} \mathrm{E}\right)$.

[9] Figure 1 shows the retrieved HCN profiles from the 10 balloon flights. The precision of the HCN retrieval, derived from the residual of the spectral fits, is about 530 ppt. The largest contribution to the systematic errors are the spectroscopic parameters of the HCN lines, which cause a systematic uncertainty of $10 \%$ [Rothman et al., 2005]. A high variability in $\mathrm{HCN}$ is observed in the troposphere. Above the tropopause $(\sim 12-14 \mathrm{~km}$ at mid-latitudes, $\sim 8-$ $10 \mathrm{~km}$ at polar latitudes) the HCN VMRs are more constant, around 220 ppt. In the stratosphere HCN decreases with altitude. The decrease is considerably faster in the polar profiles than in the mid-latitude profiles. This is typical for a trace gas with a source in the troposphere and a sink in the upper stratosphere, and is caused by the atmospheric large scale circulation. The fastest HCN decrease is observed inside the polar vortex, where diabatic descent of the airmasses had occurred (Dec. 1999, Mar. 2000, Dec. 2002). We note that both mid-latitude and polar data sets agree well with historic measurements from literature sources.

[10] To further assess the tracer characteristics of HCN we next consider the $\mathrm{HCN}$ profiles on isopleths of the long-lived stratospheric tracers $\mathrm{CH}_{4}$ (Figure 2) and $\mathrm{N}_{2} \mathrm{O}$ (see auxiliary material). This should remove the variability

\footnotetext{
${ }^{1}$ Auxiliary material is available at $\mathrm{ftp}: / / \mathrm{ftp}$. agu.org/apend/gl/ $2006 \mathrm{gl026015.}$
}

induced by the large scale circulation [Plumb and Ko, 1992]. Both tracers were measured simultaneously with $\mathrm{HCN}$ in the same airmass by the MkIV instrument. $\mathrm{CH}_{4}$ has its source in the troposphere and destruction in the stratosphere occurs mainly by the reaction with $\mathrm{OH} . \mathrm{N}_{2} \mathrm{O}$ is also produced in the troposphere, in the stratosphere it is destroyed by photolysis and by the reaction with $\mathrm{O}\left({ }^{1} \mathrm{D}\right)$. The correlations are very compact, confirming the long lifetime of stratospheric $\mathrm{HCN}$, and that latitudinal differences are mainly caused by large scale circulation.

\section{Model Comparisons}

[11] We compare the retrieved HCN VMRs and tracer correlations with $\mathrm{HCN}$-tracer correlations calculated by a 2-dimensional model [Weisenstein et al., 2004]. The model runs were performed with a resolution of $9.5^{\circ}$ in latitude and $1.2 \mathrm{~km}$ in altitude. The 2-D residual circulation and eddy diffusion coefficients were calculated from observed climatological values of temperature, $\mathrm{H}_{2} \mathrm{O}$, zonal wind, and ozone [Fleming et al., 1999]. Rate coefficients for chemical reactions were taken from Sander et al. [2003], photolysis cross-sections from Sander et al. [2000]. The model was initialized with a uniform VMR of $220 \mathrm{ppt}$ $\mathrm{HCN}$ at the surface, leading to VMRs slightly lower at the tropopause.

[12] In total, 7 model runs were performed in which different parameters were used for the HCN chemistry. The main considerations were the different recommendations for the reaction of $\mathrm{HCN}$ with $\mathrm{OH}$, the destruction of $\mathrm{HCN}$ by photolysis, and the plausibility of $\mathrm{HCN}$ as a product of the reaction of $\mathrm{CH}_{3} \mathrm{CN}$ with $\mathrm{OH}$. As no measured UV absorption cross sections are available at wavelengths greater than $160 \mathrm{~nm}$, photolysis was considered by using the absorption cross sections of $\mathrm{HCl}$ as had been done previously [Cicerone and Zellner, 1983; Brasseur et al., 1985]. The reactions and their rate coefficients used in the different model runs are summarized in Table 1.

[13] Figure 2 (middle) shows the results of the model runs that used the recommendations for the $\mathrm{HCN}$ 


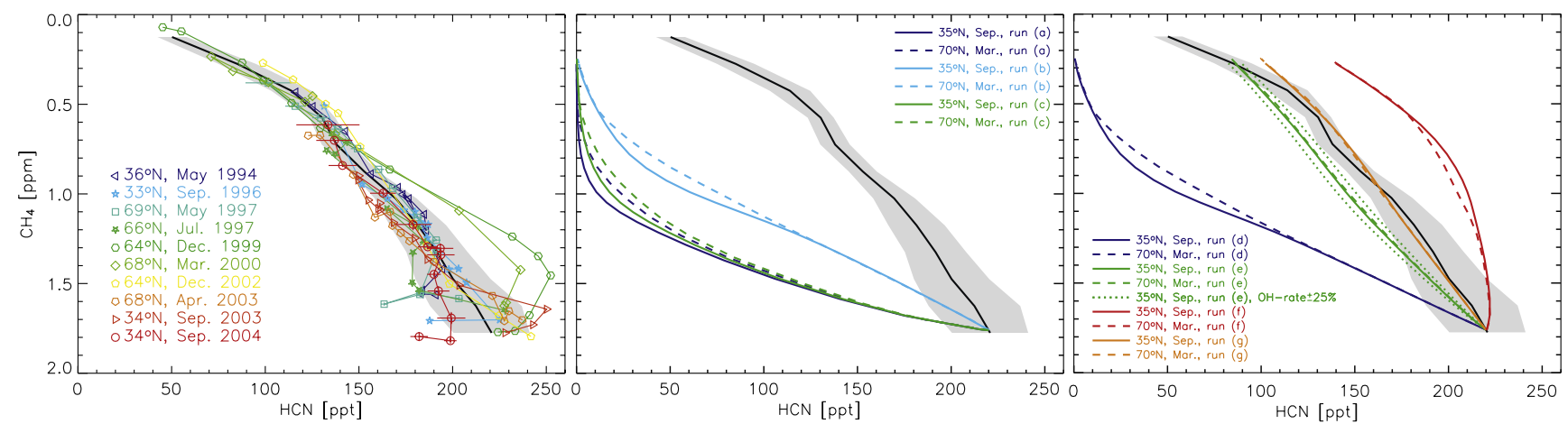

Figure 2. (left) Retrieved vertical profiles of $\mathrm{HCN}$ vs. $\mathrm{CH}_{4}$, measured simultaneously by the MkIV instrument. The black line is an average of all measurements created by averaging the HCN VMRs in bins of $0.15 \mathrm{ppm} \mathrm{CH}_{4}$ with the gray shaded area giving the standard deviation. (middle) MkIV average vs. $\mathrm{CH}_{4}$ compared to model runs using old $\mathrm{HCN}$ reaction rates from Sander et al. [2003] and Cicerone and Zellner [1983]. (right) MkIV average vs. $\mathrm{CH}_{4}$ compared to model runs using the new HCN chemistry. For a detailed description of the individual model runs see Table 1.

destruction by $\mathrm{OH}$ of Sander et al. [2003] and for the destruction of $\mathrm{O}\left({ }^{1} \mathrm{D}\right)$ of Cicerone and Zellner [1983]. Run "a" also includes photolysis. For comparison with the measurements, the model output at $35^{\circ} \mathrm{N}$ and at $70^{\circ} \mathrm{N}$ was taken and compared to the average profile of the MkIV measurements on isopleths of $\mathrm{CH}_{4}$. Run "a" substantially underestimates the amount of $\mathrm{HCN}$ in the stratosphere. The modeled HCN VMR is below 30 ppt already at a $\mathrm{CH}_{4}$ level of $1 \mathrm{ppm}$, whereas the measured HCN VMR is still greater than $160 \mathrm{ppt}$. Ignoring the destruction of HCN by $\mathrm{OH}$ as done in run "b" we obtain modeled profiles that are slightly closer to the measurements but with the HCN amount in the stratosphere still severely underestimated. This suggests that the $\mathrm{HCl}$ photolysis cross sections are not a good surrogate for HCN. Run "c" shows the modeled HCN VMR if photolysis is neglected and only destruction by $\mathrm{OH}$ and $\mathrm{O}\left({ }^{1} \mathrm{D}\right)$ is taken into account. The result is nearly identical to run "a", showing that the loss of $\mathrm{HCN}$ is dominated by the fast destruction by reaction with $\mathrm{OH}$.

[14] New rate coefficients for the reactions of $\mathrm{HCN}$ with $\mathrm{OH}$ and $\mathrm{O}\left({ }^{1} \mathrm{D}\right)$ have recently been measured [Strekowski, 2001]. The experimental methods used for the rate coefficient measurements are described in Hynes and Wine
[1996] and Strekowski et al. [2000]. Details of the $\mathrm{OH}+$ $\mathrm{HCN}$ and $\mathrm{O}\left({ }^{1} \mathrm{D}\right)+\mathrm{HCN}$ studies will be published elsewhere. Runs "d"- "g" in Figure 2 (right) show the results of model calculations applying these new rate coefficients. Run " $\mathrm{d}$ " also includes photolysis based on $\mathrm{HCl}$ cross sections. We see a modeled HCN profile similar to runs " $a$ " and " $b$ ", indicating that also in this run the destruction by photolysis seems unrealistically high. Run "e" neglects photolysis and applies only the destruction mechanisms by $\mathrm{OH}$ and $\mathrm{O}\left({ }^{1} \mathrm{D}\right)$. This model run gives a more reasonable representation with the measured $\mathrm{HCN}$ profile, with agreement within the error bars in the lowermost stratosphere $\left(1.5-1.7 \mathrm{ppm} \mathrm{CH}_{4}\right)$ and in the upper stratosphere $\left(\sim 0.3 \mathrm{ppm} \mathrm{CH}_{4}\right)$. In the middle stratosphere a slight underestimate of the measured HCN VMRs by up to $\sim 20 \mathrm{ppt}$ remains. The change in the modeled HCN profile in run "e" compared to run "c" is dominated by the change in the rate of the reaction with $\mathrm{OH}$ because the rate of the reaction with $\mathrm{O}\left({ }^{1} \mathrm{D}\right)$ differs only by $10-30 \%$ from the estimate by Cicerone and Zellner [1983].

[15] The dotted lines in Figure 2 show the resulting HCN profile if the rate of the reaction with $\mathrm{OH}$ is increased/ decreased by $25 \%$, a conservative estimate of the accuracy of the rate coefficient. Considering this uncertainty, we

Table 1. Reaction Rates Used for the Different Model Runs

\begin{tabular}{|c|c|c|c|}
\hline Reaction & Rate Coefficients & Used in Model Run & Reference \\
\hline $\mathrm{HCN}+\mathrm{OH} \rightarrow$ products $^{\mathrm{a}}$ & $A=1.2 \cdot 10^{-13}, \frac{E_{a}}{R}=400$ & $\mathrm{a}, \mathrm{c}$ & Sander et al. [2003] \\
\hline $\mathrm{HCN}+\mathrm{O}\left({ }^{1} \mathrm{D}\right) \rightarrow$ products $^{\mathrm{b}}$ & $k=1 \cdot 10^{-10}$ & $a, b, c$ & Cicerone and Zellner [1983] \\
\hline $\mathrm{HCN}+\mathrm{h} \nu \rightarrow$ products & absorption cross sections of $\mathrm{HCl}$ & $a, b, d$ & Sander et al. $[2000]$ \\
\hline $\mathrm{HCN}+\mathrm{OH} \rightarrow$ products $^{\mathrm{c}}$ & $\begin{array}{c}k_{0}=4.28 \cdot 10^{-33} \\
k_{\infty}=4.25 \cdot 10^{-13} e^{-\frac{1150}{T}} \\
F_{c}=0.8\end{array}$ & $\mathrm{~d}, \mathrm{e}, \mathrm{f}, \mathrm{g}$ & Strekowski [2001] \\
\hline $\mathrm{HCN}+\mathrm{O}\left({ }^{1} \mathrm{D}\right) \rightarrow$ products $^{\mathrm{a}, \mathrm{d}}$ & $A=7.7 \cdot 10^{-11}, \frac{E_{a}}{R}=-100$ & $\mathrm{~d}, \mathrm{e}, \mathrm{f}, \mathrm{g}$ & Strekowski [2001] \\
\hline $\mathrm{CH}_{3} \mathrm{CN}+\mathrm{OH} \rightarrow$ products $^{\mathrm{a}, \mathrm{e}}$ & $A=7.8 \cdot 10^{-13}, \frac{E_{a}}{R}=1050$ & $f, g$ & Sander et al. [2003] \\
\hline
\end{tabular}

a Rate coefficient is expressed by $k=A \cdot e^{\left(-\frac{E a}{R T}\right)}$, where $\mathrm{A}$ is given in $\frac{\mathrm{cm}^{3}}{\text { molec. } \cdot S}$ and $T$ is the temperature in $\mathrm{K}$.

${ }^{\mathrm{b}}$ Rate coefficient (given in $\frac{\mathrm{cm}^{3}}{\text { molec. } \cdot s}$ ) is assumed constant throughout the atmosphere. molec. $\cdot s$
cTermolecular reaction parameterized as $k=\frac{k_{0}[M] \cdot k_{\infty}}{k_{0}[M]+k_{\infty}} \cdot F_{c}\left(1+\left(\lg \left(k_{0}[M] / k_{\infty}\right)\right)^{2}\right)^{-1}$, with $k_{0}$ in $\frac{\mathrm{cm}^{6}}{{\text { molec } .^{2} \cdot s}_{s}}$ and $k_{\infty}$ in $\frac{\mathrm{cm}^{3}}{\text { molec. } \cdot s}$, $[M]$ is the molecular air
density.

${ }^{\mathrm{d}}$ Rate coefficient given is for forming products other than $\mathrm{HCN}+\mathrm{O}\left({ }^{3} \mathrm{P}\right)$.

${ }^{\mathrm{e}} \mathrm{An} \mathrm{HCN}$ yield of $100 \%$ and $30 \%$ was assumed for the runs $\mathrm{f}$ and g, respectively. 
achieve reasonable agreement between the measured HCN profile and the one modeled in run " $\mathrm{e}$ ".

[16] In early studies on the HCN chemistry a link between $\mathrm{HCN}$ and $\mathrm{CH}_{3} \mathrm{CN}$ had been suggested [Murad et al., 1984; Brasseur et al., 1985]. More recently Tyndall et al. [2001] studied the products of $\mathrm{Cl}$ - and $\mathrm{OH}$-initiated oxidation of $\mathrm{CH}_{3} \mathrm{CN}$ in the laboratory. They report that $\mathrm{Cl}$ initiated oxidation of $\mathrm{CH}_{3} \mathrm{CN}$ leads to the formation of $\mathrm{HC}(\mathrm{O}) \mathrm{CN}$, the fate of which is to produce $\mathrm{HCN}$ with a yield of $50 \%$. In the $\mathrm{OH}$-initiated oxidation they report an $\mathrm{HC}(\mathrm{O}) \mathrm{CN}$ yield of $(40 \pm 20) \%$, however, no other carbon bearing products could be unambiguously identified. We therefore consider the influence of a potential yield of $\mathrm{HCN}$ from the destruction of $\mathrm{CH}_{3} \mathrm{CN}$ by the reaction with $\mathrm{OH}$ (see Table 1), which is the dominant loss reaction of $\mathrm{CH}_{3} \mathrm{CN}$ in the stratosphere. $\mathrm{CH}_{3} \mathrm{CN}$ has been initialized in the model with a tropospheric value of $150 \mathrm{ppt}$. The $\mathrm{CH}_{3} \mathrm{CN}$ chemistry in the model is the same as in Kleinböhl et al. [2005], which has shown to give excellent agreement with recent infrared measurements of stratospheric $\mathrm{CH}_{3} \mathrm{CN}$.

[17] Run "f" in Figure 2 shows the modeled HCN profile in the case of $100 \%$ production of $\mathrm{HCN}$ from the reaction $\mathrm{CH}_{3} \mathrm{CN}+\mathrm{OH}$. It can be seen that this produces a significant overestimation of the HCN VMR in the stratosphere. However, if a yield of $30 \%$ of HCN is assumed (run "g" in Figure 2) one obtains a model profile that is closer to the measurements than the profile of run " $\mathrm{e}$ " in which no HCN production had been assumed.

\section{Summary and Implications}

[18] Measurements of the stratospheric distribution of HCN by infrared solar occultation spectrometry provide new constraints on its photochemical lifetime. HCN is found to be highly correlated with longlived tracers such as $\mathrm{CH}_{4}$ and $\mathrm{N}_{2} \mathrm{O}$, suggesting its stratospheric lifetime is much longer than calculated using accepted chemistry [Sander et al., 2003].

[19] Using a 2D-model, we have investigated the chemistry of $\mathrm{HCN}$ and find that recently reported measurements of the rate coefficient for the main sink, the reaction with $\mathrm{OH}$, give reasonable agreement between the calculated and measured profiles. This result is achieved assuming that the loss of HCN via photolysis is negligible. We estimate that the photochemical lifetime of HCN is $\gtrsim 10$ years in the stratosphere below $30 \mathrm{~km}$ and $\gtrsim 5$ years in the upper troposphere - about an order of magnitude longer than estimated using the currently accepted chemistry (see auxiliary material). We note that the tropospheric $\mathrm{HCN}$ lifetime against oxidation is considerably larger than against uptake into the ocean ( $\sim 6$ months, [Li et al., 2003]). Finally, these observations do not rule out a substantial yield $(\sim 30 \%)$ of $\mathrm{HCN}$ from the reaction of $\mathrm{CH}_{3} \mathrm{CN}$ with $\mathrm{OH}$.

[20] Further improvement in HCN modeling at upper stratospheric and mesospheric altitudes can be expected once measurements of absorption cross-sections and quantum yields for the photolysis of $\mathrm{HCN}$ become available.

[21] Acknowledgments. We would like to thank the various launch crews for conducting the balloon flights, and D. Petterson and J. Landeros of JPL for their excellent support prior and during the measurement campaigns. Work at AER was supported by the NASA ACMAP program. Work at Georgia Tech was supported by the NASA UARP program. Work at Jet Propulsion Laboratory, California Institute of Technology, was performed under a contract with the National Aeronautics and Space Administration.

\section{References}

Abbas, M. M., et al. (1987), Stratospheric distribution of $\mathrm{HCN}$ from far infrared observations, Geophys. Res. Lett., 14, 531-534.

Brasseur, G., R. Zellner, A. De Rudder, and E. Arjis (1985), Is hydrogen cyanide a progenitor of acetonitrile in the atmosphere?, Geophys. Res. Lett., 12, 117-120.

Carli, B., F. Mencaraglia, and A. Bonetti (1982), New assignments in the submillimeter emission spectrum of the stratosphere, Int. J. Infrared Millimeter Waves, 3, 385-394.

Cicerone, R. J., and R. Zellner (1983), The atmospheric chemistry of hydrogen cyanide (HCN), J. Geophys. Res., 88, 10,689-10,696.

Coffey, M. T., W. G. Mankin, and R. J. Cicerone (1981), Spectroscopic detection of stratospheric hydrogen cyanide, Science, 214, $333-335$.

Fleming, E. L., C. H. Jackman, R. S. Stolarski, and D. B. Considine (1999), Simulation of stratospheric tracers using an improved empirically based two-dimensional model transport formulation, J. Geophys. Res., 104, 23,911-23,934.

Hynes, A. J., and P. H. Wine (1996), The atmospheric chemistry of dimethylsulfoxide (DMSO), J. Atmos. Chem., 24, 23-37.

Jaramillo, M., R. L. de Zafra, J. W. Barrett, A. Parrish, and P. M. Solomon (1988), MM-wave observations of stratospheric HCN at tropical latitudes, Geophys. Res. Lett., 15, 265-268.

Jaramillo, M., R. L. de Zafra, J. Barrett, L. K. Emmons, P. M. Solomon, and A. Parrish (1989), Measurements of stratospheric hydrogen cyanide at McMurdo Station, Antarctica: Further evidence of winter stratospheric subsidence?, J. Geophys. Res., 94, 16,773-16,777.

Kasai, Y. J., A. Kagawa, N. Jones, A. Fujiwara, K. Seki, Y. Murayama, and F. Murcray (2005), Seasonal variations of CO and HCN in the troposphere measured by solar absorption spectroscopy over Poker Flat, Geophys. Res. Lett., 32, L19812, 10.1029/2005GL022826.

Kleinböhl, A., G. C. Toon, B. Sen, J. L. Blavier, D. K. Weisenstein, and P. O. Wennberg (2005), Infrared measurements of atmospheric $\mathrm{CH}_{3} \mathrm{CN}$, Geophys. Res. Lett., 32, L23807, 10.1029/2005GL024283.

Li, Q., D. J. Jacob, R. M. Yantosca, C. L. Heald, H. B. Singh, M. Koike, Y. Zhao, G. W. Sachse, and D. G. Streets (2003), A global threedimensional model analysis of the atmospheric budgets of $\mathrm{HCN}$ and $\mathrm{CH}_{3} \mathrm{CN}$ : Constraints from aircraft and ground measurements, J. Geophys. Res., 108(D21), 8827, 10.1029/2002JD003075.

Murad, E., W. Swider, R. A. Moss, and S. Toby (1984), Stratospheric sources of $\mathrm{CH}_{3} \mathrm{CN}$ and $\mathrm{CH}_{3} \mathrm{OH}$, Geophys. Res. Lett., 11, 147-150.

Plumb, R. A., and M. K. W. Ko (1992), Interrelationships between mixing ratios of long-lived stratospheric constituents, J. Geophys. Res., 97, $10,145-10,156$

Rinsland, C. P., A. H. Smith, P. L. Rinsland, A. Goldman, J. W. Brault, and G. M. Stokes (1982), Ground-based infrared spectroscopic measurements of hydrogen cyanide, J. Geophys. Res., 87, 11,119-11,125.

Rinsland, C. P., G. Dufour, C. D. Boone, P. F. Bernath, and L. Chiou (2005), Atmospheric Chemistry Experiment (ACE) measurements of elevated Southern Hemisphere upper tropospheric $\mathrm{CO}, \mathrm{C}_{2} \mathrm{H}_{6}, \mathrm{HCN}$, and $\mathrm{C}_{2} \mathrm{H}_{2}$ mixing ratios from biomass burning emissions and longrange transport, Geophys. Res. Lett., 32, L20803, 10.1029/ 2005GL024214.

Rothman, L. S., et al. (2005), The HITRAN 2004 molecular spectroscopic data base, J. Quant. Spectrosc. Radiat. Transfer, 96, 139-204.

Sander, S. P., et al. (2000), Chemical kinetics and photochemical data for use in stratospheric modeling, Evaluation 13, Tech. Rep. Publ. 00-3, Jet Propul. Lab., Pasadena, Calif.

Sander, S. P., et al. (2003), Chemical kinetics and photochemical data for use in atmospheric studies: Evaluation 14, Tech. Rep. Publ. 02-25, Jet Propul. Lab., Pasadena, Calif.

Schneider, J., V. Bürger, and F. Arnold (1997), Methyl cyanide and hydrogen cyanide measurements in the lower stratosphere: Implications for methyl cyanide sources and sinks, J. Geophys. Res., 102, 25,50125,506.

Singh, H. B., et al. (2003), In situ measurements of $\mathrm{HCN}$ and $\mathrm{CH}_{3} \mathrm{CN}$ over the Pacific Ocean: Sources, sinks, and budgets, J. Geophys. Res., 108(D20), 8795, doi:10.1029/2002JD003006.

Spreng, S., and F. Arnold (1994), Balloon-borne mass spectrometer measurements of $\mathrm{HNO}_{3}$ and $\mathrm{HCN}$ in the winter Arctic stratosphere-Evidence for HNO3-processing by aerosols, Geophys. Res. Lett., 21, $1251-1254$. 
Strekowski, R. S. (2001), Laser flash photolysis studies of some $\mathrm{O}\left({ }^{1} \mathrm{D}_{2}\right)$ and $\mathrm{OH}\left(\mathrm{X}^{2} \Pi\right)$ reactions of atmospheric interest, Ph.D. thesis, Georgia Institute of Technology, Atlanta, Ga.

Strekowski, R. S., J. M. Nicovich, and P. H. Wine (2000), Quenching of $\mathrm{O}\left({ }^{1} \mathrm{D}_{2}\right)$ by $\mathrm{Cl}_{2} \mathrm{CO}$, Chem. Phys. Lett., 330, 354-360.

Toon, G. C. (1991), The JPL Mk IV interferometer, Opt. Photonics News, 2 , $19-21$.

Tyndall, G. S., J. J. Orlando, T. J. Wallington, and M. D. Hurley (2001), Products of the Cl-atom- and $\mathrm{OH}$-radical-initiated oxidation of $\mathrm{CH}_{3} \mathrm{CN}$, J. Phys. Chem. A, 105, 5380-5384.

Weisenstein, D. K., J. Eluszkiewicz, M. K. W. Ko, C. J. Scott, C. H. Jackman, E. L. Fleming, D. B. Considine, D. E. Kinnison, P. S. Connell, and D. A. Rotman (2004), Separating chemistry and transport effects in two-dimensional models, J. Geophys. Res., 109, D18310, doi:10.1029/ 2004JD004744.

Zander, R., C. P. Rinsland, C. B. Farmer, J. Namkung, R. H. Norton, and J. M. Russell III (1988), Concentrations of carbonyl sulfide and hydrogen cyanide in the free upper troposphere and lower stratosphere deduced from ATMOS/spacelab 3 infrared solar occultation spectra, J. Geophys. Res., 93, 1669-1678.

J.-F. L. Blavier, A. Kleinböhl, B. Sen, and G. C. Toon, Jet Propulsion Laboratory, Mail-Stop 183-501, 4800 Oak Grove Drive, Pasadena, CA 91109, USA. (armin.kleinboehl@jpl.nasa.gov)

J. M. Nicovich and P. H. Wine, School of Chemistry and Biochemistry, Georgia Institute of Technology, 770 State Street, Atlanta, GA 30332 0400, USA.

R. S. Strekowski, School of Earth and Atmospheric Science, Georgia Institute of Technology, 311 Ferst Drive, Atlanta, GA 30332, USA.

D. K. Weisenstein, Atmospheric and Environmental Research, Inc., 131 Hartwell Avenue, Lexington, MA 02421, USA.

P. O. Wennberg, California Institute of Technology, Mail-Stop 150-21, 1200 E. California Blvd., Pasadena, CA 91125, USA. 